\title{
Ecophenotypic variation in Mutilus pumilus (Ostracoda) from Australia, studied by canonical variate analysis and tensor biometrics
}

\author{
R. A. REYMENT ${ }^{1}$, F. L. BOOKSTEIN ${ }^{2}$, K. G. McKENZIE ${ }^{3}$ \& S. MAJORAN ${ }^{1}$ \\ ${ }^{1}$ Paleontologiska Institutionen, Uppsala Universitet, Box 558, S-751 22 Uppsala, Sweden \\ ${ }^{2}$ Center for Human Growth and Development, University of Michigan, Ann Arbor, \\ Michigan 48109, U.S.A. \\ ${ }^{3}$ School of Applied Science, Riverina-Murray Institute of Higher Education, P.O. Box 588, \\ Wagga Wagga, N.S.W. 2650, Australia
}

\begin{abstract}
Ecophenotypic variation in the ornament of living Mutilus pumilus from Australia may be related to seasonal temperature differences along the southern coasts. Standard methods of statistical analysis identify geographical differences in the morphology of the data, but are inadequate for analysing the complex patterns of shape variability in the species. Geometric morphometric methods localised the more important changes in shape in both the outline of the shell and in the configuration of the ornament.
\end{abstract}

\section{INTRODUCTION}

For species of marine ostracods, water chemistry may affect ornamental details, the outline of the shell, and size (which is always labile in crustaceans). Salinity is doubtless one of the major chemical factors involved; for a discussion of this and others, particularly temperature, see Bodergat (1983) and Hartmann (1982). Because ostracods display evolutionary polymorphism as well as ecophenotypy (Ducasse, 1981, 1983; Ducasse \& Cirac, 1981; Ducasse \& Rousselle, 1979; Hartmann, 1982; Keen, 1982; Reyment 1963, 1983), we should like to find quantitative expressions of this chemically induced variability in the architecture of the shell. In this connection, shape, size and ornament are of equal interest.

A detailed charting of the expression of phenotypic polymorphism in the shell is necessary if we are to distinguish environmentally mediated changes in the characteristics of the ostracod shell from other changes having lasting evolutionary significance (Abe, 1983; Reyment, 1985; Reyment, in press).

Morphs which moult at periods of relatively low temperature (say, at night) will have less heavily carbonated shells than those which moult during the day when temperatures in tropical and temperate tidal pools can reach, and exceed, $40^{\circ} \mathrm{C}$, thereby providing a carbonate in the ambient medium and bringing about more heavily calcified shells.

Corresponding to the various kinds of polymorphic expression in the Ostracoda are several statistical methods for their analysis. We shall analyse the standard size-measures of the carapace by multivariate statistical analysis and contrast the findings with descriptors of variation in shape yielded by the analysis of landmarks (Bookstein et al., 1985; Bookstein, 1986).
Our analyses exploit two classes of characters: linear distances and locations of landmarks.

\section{PROVENANCE OF THE MATERIAL}

The specimens analysed in this paper were collected by one of us (KGM) from various nearshore sites around the coastlines of South Australia and Victoria. Further samples from beach sands at Eucla (West Australia) and Robe (South Australia) were kindly supplied by Mr. J. V. Neil. The localities from which the material was collected are indicated on the map in Fig. 1, along with the places sampled by Hartmann (1982).

\section{THE MEASURES}

The distance measures comprise a truss (Bookstein et al., 1985) of 17 variables trellised across the carapace and centred around features of the ornament, together with the length of the carapace. These characters are displayed in Fig. 2A. Note that the trellised network is overdetermined: there are two measures (10 and 17) in addition to those required to triangulate the nine endpoints.

We located two sets of landmarks. The first eight were located along a major feature of the ornamental pattern, the median rib, so as to disclose any systematic variation in this ornamental feature. The median rib is a prominent ornamental feature joining to the adductor muscle tubercle anteriorly and bifurcating posteriorly to form a Y-shaped structure. These eight loci are shown in Fig. 2B. The second set, consisting of six landmarks, comprises loci sited around the margin of the shell (Fig. 2C). Landmarks $A$ and $D$ are the anterior and posterior ends of the longest diameter of 


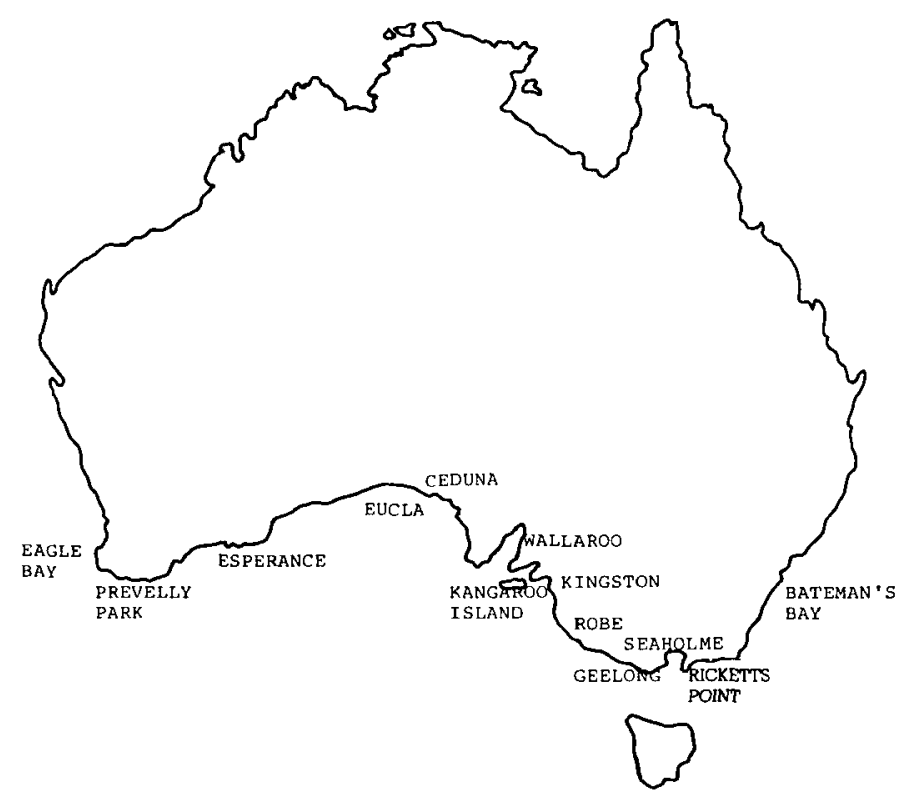

Fig. 1. Sketch showing the localities from which material for the present study was collected, and the sites sampled by Hartmann (1982).

the carapace, to be found midway within the roundings of the anterior, respectively, caudal processes; landmark $B$ is at the centre of the span of the anteroventral rib at the ventral margin. Landmark $C$ is the site at which the ventrolateral rib cuts the ventral margin, $E$ is the midpoint of the sharply rounded posterodorsal angle and $F$, the site of the eye-tubercle.

In addition, a further set of variables was computed from the figures of $M$. pumilus published by Hartmann (1982), using Lohmann's (1983) version of the ZahnRoskies (1972) representation of a form with a curving outline. Hartmann's specimens were obtained from southern West Australia, South Australia and Victoria. They span a wider geographical extent than our samples and were collected over an interval of about four months.

\section{STATISTICAL METHODS}

The classical multivariate statistical method of canonical variate analysis was applied to samples of left and right valves from five sites: Eucla in West Australia, Kingston and Robe in South Australia and Ricketts Point and Seaholme, Port Philip Bay, Victoria. We wished to ascertain what variation there was in the shape of the carapace and to what extent it differed by region.

The geometric methods of Bookstein (1986) were then applied to the variation in the position of the median rib. The eight landmark locations of the first set were analysed by shape-coordinate analysis and by the method of biorthogonal grids (Bookstein, 1986). Finally, the second set of six landmarks, those located on the outline of the shell, were analysed by the method of shape-coordinates.

\section{CANONICAL VARIATE ANALYSIS}

The 17 truss distances, together with the length of the carapace, were subjected to canonical variate analysis using an expanded and updated version of the program published by Blackith \& Reyment (1971). In univariate analyses of variance, all differences in means among the five samples are highly significant with the exception of variable 16 , which falls just short of the $5 \%$ level $(\mathrm{N}=112)$. The results of the ANOVA are given in Table 1 . This analysis strongly suggests differences in size. The best variables at the univariate level (i.e. those with the highest univariate F-ratios) are 1, 3, 13 and 15. Distances 1 and 3 relate to the anterior region; distances 13 and 15 concern the posterior extension of the carapace. The outline landmark data were found to confirm the results in regard to variables 1 and 3 .

If we now inspect the canonical variate coefficients (Table 2), it will be seen that there is little agreement with the ANOVA results. The coefficients cannot be given a logical interpretation; part of this difficulty may lie with the great number of variables involved. The graphical analysis is more informative. The plot of the canonical variate means in the plane of the first two axes divides the observations into two distinct fields, an outcome of the systematic difference between left and right valves; in addition, the five samples are ordinated with respect to average multivariate sizes. Just as in a previous study by Bookstein and Reyment (unpub.), the first canonical variate is a disguised measure of general size.

If we now consider the information provided by the Prim minimum spanning network superimposed on the plots, left and right valves separately (Fig. 3), we observe that Kingston joins to Eucla for both left and right valves. These localities are the most westerly of the set. Ricketts Point and Seaholme are adjacent both on this plot and in Port Philip Bay. Although the canonical variate analysis is of little use for unravelling shape complexities, it seems to be informative with respect to geographical relationships.

\section{ANALYSIS OF LANDMARK COORDINATES}

We analysed two sets of landmarks dealing with separate aspects of ostracod form. One set emphasised the most marked of the ornamental features, the trace of the median rib (see Fig. 2B). The other set attempted to summarise the shape of the whole carapace by landmarks located around the margin of the shell (Fig. 2B).

\section{The method of shape-coordinates}

If we follow Thompson (1942) in representing biological homology as a geometric mapping, there is 
an alternative to classical multivariate procedures for charting changes in form. Instead of dealing indirectly with homology by the separate measurement of distances across corresponding regions, we may statistically analyse the mapping function directly by sampling it at particular loci called landmarks (Bookstein, 1986).

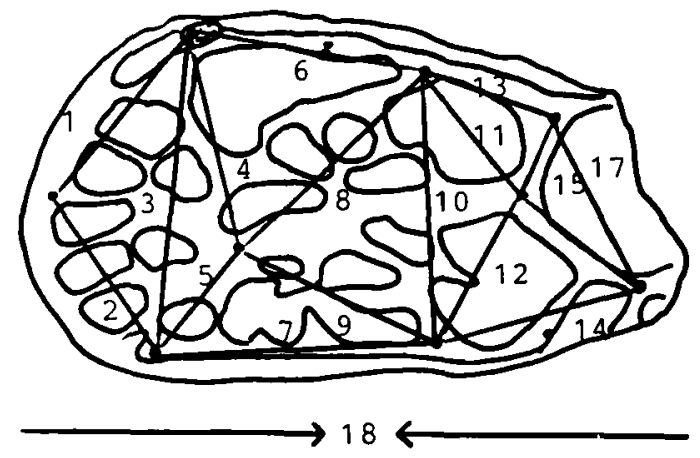

A

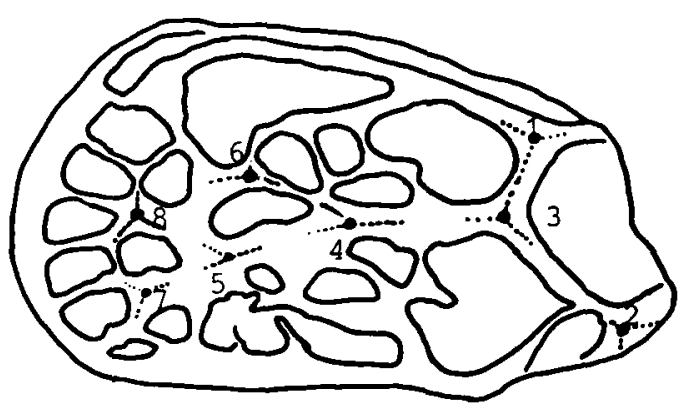

B

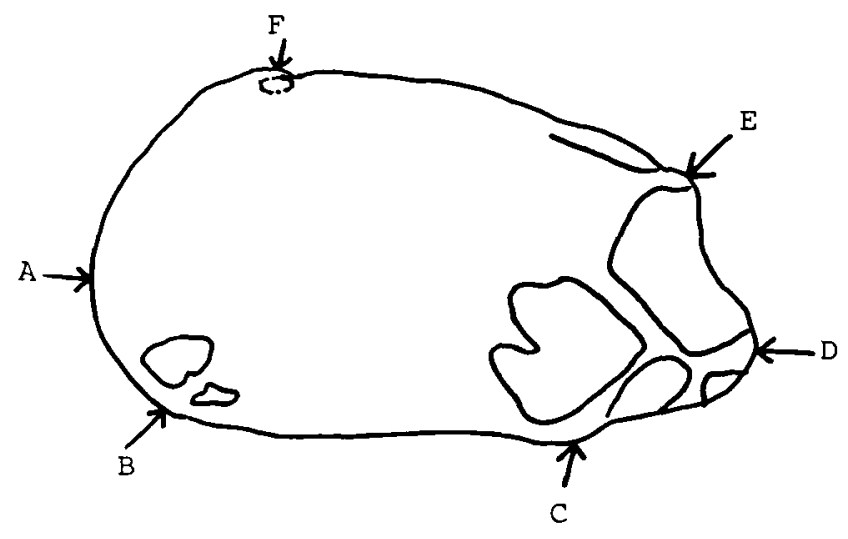

C

Fig. 2. The characters measured on Mutilus pumilus. A: Trellised network of distances measured on various features of the carapace. B: Eight landmarks located along the median rib and associated ornamental features. C: Six landmarks comprising loci sited around the margin of the shell.
Landmarks are points declared to be homologous from form to form. Several methods have been proposed over the last 20 years for the treatment of twodimensional observations of landmarks (cf. Bookstein et al., 1985). For variations in shape that are not too great, both the analysis and the interpretation of changes in the landmarks proceed effectively when the landmarks are considered three at a time in a set of triangles distributed over the form to be studied. For complete coverage of $\mathrm{N}$ landmarks, there must be at least $\mathrm{N}-2$ triangles in a rigid configuration. When this requirement is met, it does not matter which triangles are studied, as the multivariate statistical analysis of any such set is the same to terms of the first order in the variation of shape (Bookstein, 1986). Any mean differences, trends, or statistical components of shape to be found in the landmark data may be viewed as deformations by the biorthogonal diagrams of Bookstein (1978). The multivariate methods required for analysing the shape of a single triangle are adaptations of well known methods. The morphometric analysis of the shape of a triangle $\mathrm{XYZ}$ is equivalent to the ordinary normal model analysis of the single complex variable $(\mathrm{Z}-\mathrm{X}) /(\mathrm{Y}-\mathrm{X})$, which is the same as the ordinary normal model multivariate analysis of the pair of Cartesian coordinates assigned to landmark $\mathrm{Z}$ in a Cartesian system for which landmark $X$ is always located at $(0,0)$ and landmark $Y$ at $(1,0)$. This construction results in the shape coordinates of the triangle (see Bookstein et al., 1985, pp. 230-232). An example of the shape coordinates may be inspected in Fig. 6, which shows their means for four samples to a baseline taken from landmark 5 to landmark 3 . Those two landmarks are fixed at distance 1 , and all others move with respect to them without change of shape. Permutation of landmarks $X, Y$, and $Z$ results, to first order, in mere rotation and scaling of empirical scatters of these coordinates of shape so that their ordinary multivariate analysis is not altered. Here, increase is measured as the specific fractional change, in percent of starting form, in analogy to Haldane's use of the log-transform for measurement of darwins of evolutionary distance. The units of all such changes are $\mathrm{mm} / \mathrm{mm}$. It is not difficult to show (Bookstein et al., 1985 , sec. 2.1) that when rates of change are measured in this way for distances taken across a triangle of landmarks, there is a single well defined direction of maximum rate of change, and another of minimum rate of change, and these directions lie at $90^{\circ}$ to one another.

Shape change is the set of relationships among different specific rates of change of length measured in this way. The theorems of Bookstein (1986) prove that the multivariate analysis of the set of all the shape coordinates is almost independent of the choice of baseline in the construction, which is usually taken for graphical convenience, and is equivalent to the multi- 
variate analysis of all possible ratios of size variables, and thus incorporates the multivariate study of allometry in toto.

Any mean difference between groups, or any regression coefficient indicating an allometric dependency of shape upon size, can be interpreted as a deformation of the triangle of landmarks and can then be characterised by the appropriate principal directions. These directions are the pair of distances across the triangle one of which increases most and the other of which increases least from one group to another. That is, the direction that increases most, and that which increases least, as the organism grows.

\section{FINDINGS}

\section{(a) The median rib: the first set of landmarks}

Our findings for Mutilus (left valves; $\mathrm{N}=57$ ) are diagrammed in Fig. 4. Description of the differences between samples requires a space of the maximum possible dimensionality. For the four samples considered in the present connection, Kingston $(\mathrm{N}=22)$, Seaholme $(N=13)$, Ricketts Point $(N=9)$ and Eucla $(\mathrm{N}=13)$, three dimensions of shape are appropriate. We may summarise them using any independent set of three contrasts. For these data, it is convenient to compare the mean shapes of the landmark configurations between samples 1 and 2,2 and 3 , and 3 and 4 . The analysis follows displacements of landmarks 1,2 , $4,6,7$ and 8 in a coordinate system fixed at both ends of the median rib; by rotation, translation and changes of scale, landmark 5 is fixed at $(0,0)$ and landmark 3 at $(1,0)$.

Kingston versus Seaholme. This relationship is illustrated in Fig. 4A. The dominant feature of this comparison is the apparent rigid motion of the median rib with respect to landmarks $1,6,7$ and 8 of the periphery of the form in this projection. The distances relatively increasing include $1-3$ and $6-5$; the distance 5-7 shows a relative decrease. The two samples can be separated almost perfectly (see Fig. 4A) by the vector representing the net rigid component of this contrast: the vector sum of the positions of landmarks 1,7 and 8 with respect to landmark 5 in this coordinate system. The level of significance for this separation is 0.000001 , as computed by means of the Hotelling $T^{2}$. This value needs a Bonferroni correction, as it must be multiplied by the ${ }_{8} \mathrm{C}_{5}{ }_{5} \mathrm{C}_{3}=560$ ways of choosing the five points expressing the rigid motion; clearly it remains statistically significant.

Landmark 4 on the median rib seems to move in a manner in between that of the edge-points and that of the median rib. It retains its position just above line 3-5 and it maintains the angle 3-4-5 at its previous value of $173^{\circ}$. This landmark, however, moves along the median rib so that the average proportion in which it divides the segment $3-5$ increases from $43 \%$ to $48 \%$ between the samples.

Seaholme versus Ricketts Point. This contrast appears geometrically unrelated to that of the comparison between the samples from Kingston and Seaholme. The results are presented diagrammatically in Fig. 4B. We continue to describe changes in shape with respect to a baseline from landmark 5 to landmark 3 . In this reference frame, landmarks 2 and 6 proceed farther from their positions in the Kingston sample in the same apparent directions; landmarks 4 and 7 proceed back towards their relative positions in the Kingston sample (landmark 7 shifts all the way back, landmark 4 half of

Table 1. Analysis of variance for 18 distance measures (Fig. 2).

\begin{tabular}{|c|c|c|c|c|}
\hline Variable & $\begin{array}{l}\text { Between groups } \\
\text { mean squares }\end{array}$ & $\begin{array}{l}\text { Within groups } \\
\text { mean squares }\end{array}$ & $F$ & Probability \\
\hline 1 & 1.817 & 0.101 & 17.93 & $<0.00001$ \\
\hline 2 & 0.090 & 0.017 & 5.32 & $<0.00001$ \\
\hline 3 & 0.143 & 0.009 & 15.49 & $<0.00001$ \\
\hline 4 & 0.124 & 0.017 & 7.26 & $<0.00001$ \\
\hline 5 & 0.057 & 0.014 & 4.08 & 0.0002 \\
\hline 6 & 0.032 & 0.009 & 3.46 & 0.0010 \\
\hline 7 & 0.167 & 0.021 & 8.07 & $<0.00001$ \\
\hline 8 & 0.149 & 0.017 & 8.52 & $<0.00001$ \\
\hline 9 & 0.239 & 0.024 & 9.85 & $<0.00001$ \\
\hline 10 & 0.170 & 0.018 & 9.24 & $<0.00001$ \\
\hline 11 & 0.175 & 0.030 & 5.80 & $<0.00001$ \\
\hline 12 & 0.085 & 0.014 & 6.26 & $<0.00001$ \\
\hline 13 & 0.171 & 0.010 & 16.70 & $<0.00001$ \\
\hline 14 & 0.123 & 0.014 & 8.87 & $<0.00001$ \\
\hline 15 & 0.313 & 0.018 & 17.71 & $<0.00001$ \\
\hline 16 & 0.018 & 0.009 & 1.95 & 0.0529 \\
\hline 17 & 0.115 & 0.014 & 8.35 & $<0.00001$ \\
\hline 18 & 0.135 & 0.016 & 8.71 & $<0.00001$ \\
\hline
\end{tabular}




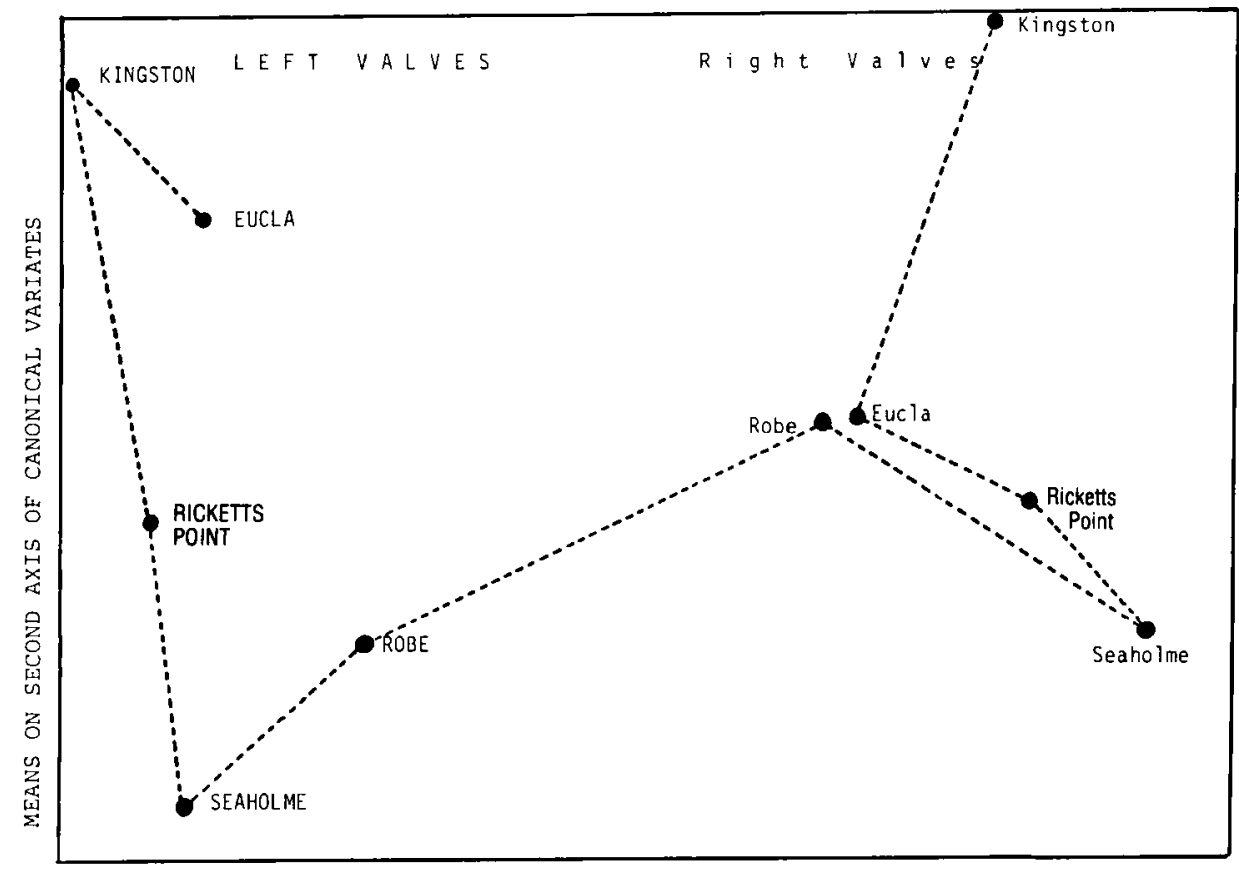

MEANS ON FIRST AXIS OF CANONICAL VARIATES

Fig. 3. Canonical variate means in the plane of the first two canonical variate vectors; the Prim minimum spanning tree is superimposed on the points for the means.

the way back), and landmarks 1 and 8 seem to move off in new directions. There appear to be no consistencies among these changes, region by region, of the ornamental pattern.

Ricketts Point versus Eucla. This contrast is represented in Fig. 4C. Here we find two regional features not previously observed. The triangle of landmarks 1,2 and 3 appear to have rotated with respect to the median rib while maintaining its shape and only slightly changing its relative size. Once again, landmarks 7 and 8 appear to move rigidly with respect to the baseline 3-5. In contrast to the comparison between Kingston and Seaholme, this motion is aligned with the direction 5-8, a distance now increasing relatively most among all inter-landmark distances of the configuration.

Interpretation. We have seen that the explicit comparison of the four samples of Mutilus generates more than three suggested shape-variables. With only four samples before us, there is no way to test whether the morphological space of these ostracods is constrained to the four aspects of shape variation we have reported in Fig. 4A-C and, moreover, no procedure by which to test whether this description is significantly better than a random walk for each landmark without any regional organisation. We have been able to reach this sceptical conclusion because of the richness of possible descriptions of size and shape; rigid motions in any direction (we have used two in our descriptions, at an angle of almost $90^{\circ}$ ), rotations, translations of single landmarks, and other forms of deformation which it was not necessary to invoke for summarising these particular contrasts.

Nonetheless, some conclusions can be drawn about methodology. It seems necessary to interpret multivariate findings in terms of point-displacements and their regional patterns. Although the 18 variables of the canonical variate analysis in the foregoing section were, in fact, distances measured among a set of landmarks, so that their analytical treatment is equivalent to an analysis of the positions of the landmarks that were studied. it is not possible to interpret the results of the canonical variate study by displacement vectors of these point-positions or in any other way. The canonical variate analysis has adjusted its findings according to a within-group correlation matrix that is composed of both true sample shape-patterns and the artefact of measurements sharing end-points (cf. Bookstein. 1986). The canonical variates may themselves actually be reporting true between-sample patterns, or, instead, aspects of within-sample variation not encountered between samples (i.e. the foreshortening effect inherent in the method).

In the resulting canonical variate vectors, any contrasting pair of coefficients may be expressing a failure of between-group differences to align with withingroup variation, a true relative increase in one measured length with respect to the whole configuration, or merely a displacement of a common end-point between 
Table 2. Summary of the Canonical Variate Analysis for 18 variables.

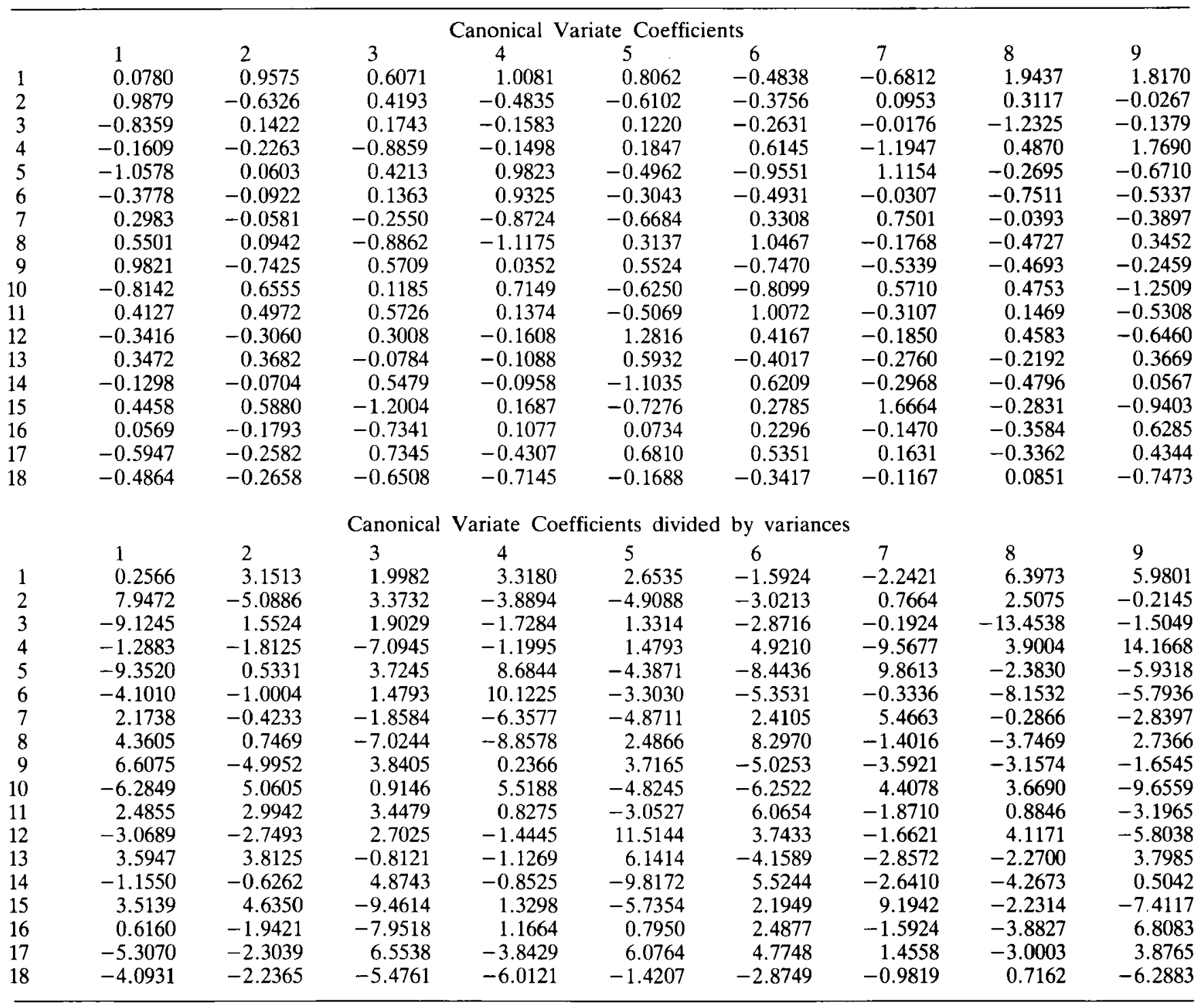

two others both fixed in position. Without an understanding of the relative movements of all landmarks, we cannot interpret any of the computed coefficients. We conclude that however great a separation is found by canonical variate analysis, biological insight into their import for shape proceeds mainly via the direct geometrical study of landmark locations.

The marked separation between Seaholme and Kingston in Fig. 5 is perhaps an expression of ecophenotypy. As Hartmann (1982) noted, these localities are widely separated in space and are subjected to different temperature regimes. We meet, then, a kind of continuous polymorphic condition, as it were. The subtle differences in the characteristics of the ribbing would be detectable even by these few landmarks in samples that reflect extreme conditions. Such ecophenotypic variation must be sequestered in the study of longer evolutionary sequences in which genetically significant polymorphisms may occur (cf. Reif, 1984).

The method of biorthogonal grids applied to the ornamental features. The method of biorthogonal grids (Bookstein, 1978, 1986) is a way of visualising a mean change in one landmark configuration. At every point of a smoothly interpolated mapping, a pair of local principal strains may be extracted from the derivative of the mapping. The resulting implied deformation of little bits of tissue from the starting form may be illustrated as crosses drawn at the points of the original square mesh. These crosses constitute a smooth symmetric tensor field defined everywhere throughout the interior of the landmark polygon. Each cross is to be read as the pair of diameters of an ellipse into which a little circle is deformed; thus, one of the pair represents the largest ratio of homologous line elements, and the other the smallest, between the means. 
Mean coordinates for the landmark of the Kingston and Seaholme samples were analysed by this procedure. The results are illustrated in Fig. 6. The rigid motion, as it were, dominating our previous report of this change is here interpreted instead: as a nearly homogenous shearing relative increase along directions like 5-6 together with relative decrease in the perpendicular direction (5-7). Landmark 4 does not conform with this model and we note also a hint of a pattern of azimuthal change: distances around the bottom form apparently contract to a greater extent than distances taken toward the upper central margin.

(b) Second landmark set (around the outline)

The six landmarks located around the circumference of the carapace (Fig. 2C) were subjected to a shapecoordinate analysis, just as the eight of the first set were studied. Triangles ABD (the anteroventral intersection), ACD (the posterior intersection), AED (the posterodorsal angle), and AFD (the eye tubercle) were
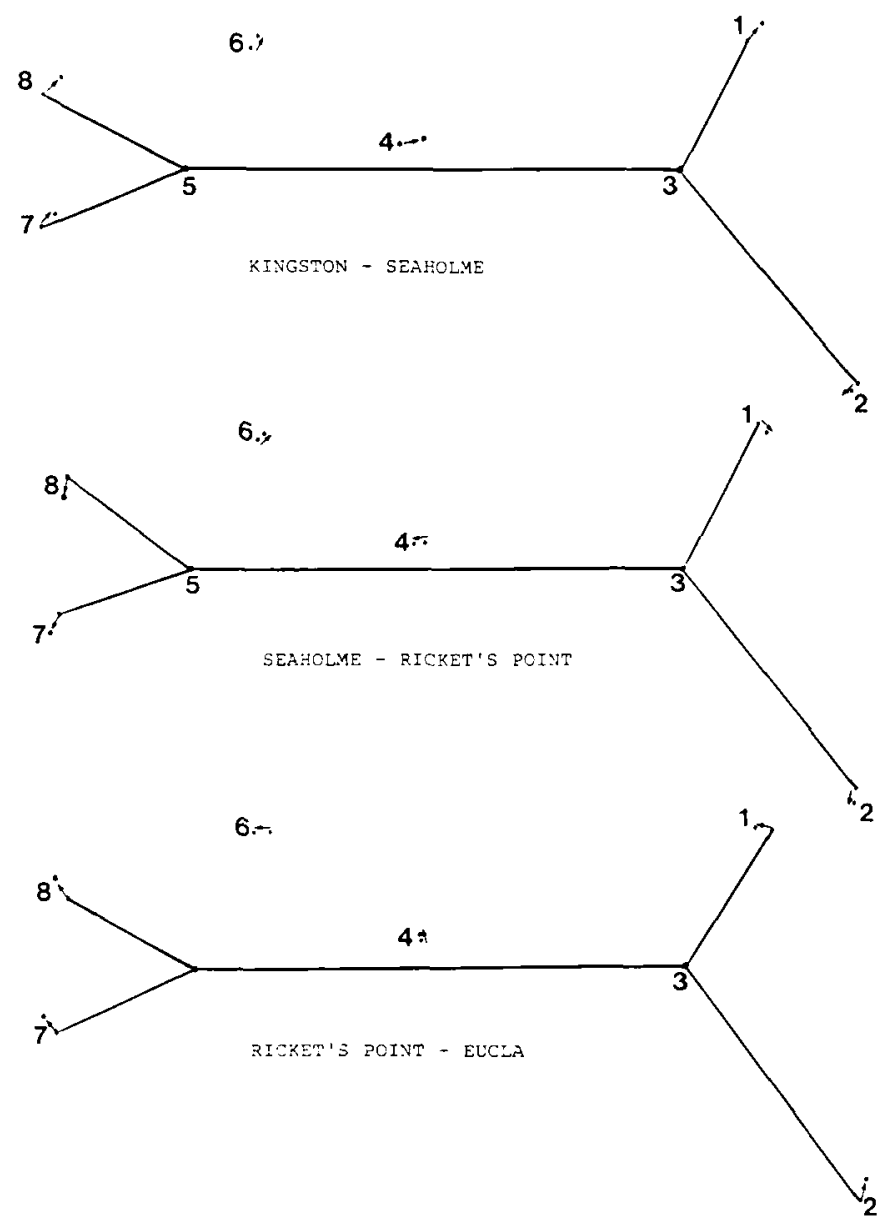

Fig. 4. Shape-coordinate analysis for three comparisons of samples. A: The Kingston and Seaholme samples contrasted. B: The Ricketts Point and Eucla samples contrasted. C: The Seaholme and Ricketts Point samples contrasted. analysed. Of these combinations, only the first, triangle $\mathrm{ABD}$ is informative. Fig. 7 displays the shape coordinates of this triangle for right valves, using the segment $\mathrm{AD}$ as baseline.

The fields for Kingston and Seaholme are remarkably similar in shape but overlap only slightly. The fields for Eucla and Robe overlie each other in the extreme left of the graph. They cut into the field staked out by the points for Seaholme, but are completely separated from the field for Kingston.

As we already saw in the canonical variate analysis, Kingston and Robe, while geographically adjacent, are shaped rather differently. On the other hand, Eucla and Robe, which are far apart on the map, agree in the shapes of their shells. This finding further supports the earlier suggestion that one or more seasonal ecological factors, such as temperature, could be the primary cause of the variability observed in the shape of the carapace of Mutilus pumilus. Our reasons for this interpretation are given in the next section. As the other combinations of landmarks did not disclose substantial differences in shape, it appears that the anteroventral zone of the carapace is the part most susceptible to ecological influences.

We have presented an analysis of right valves only, since the results for left valves are essentially the same.

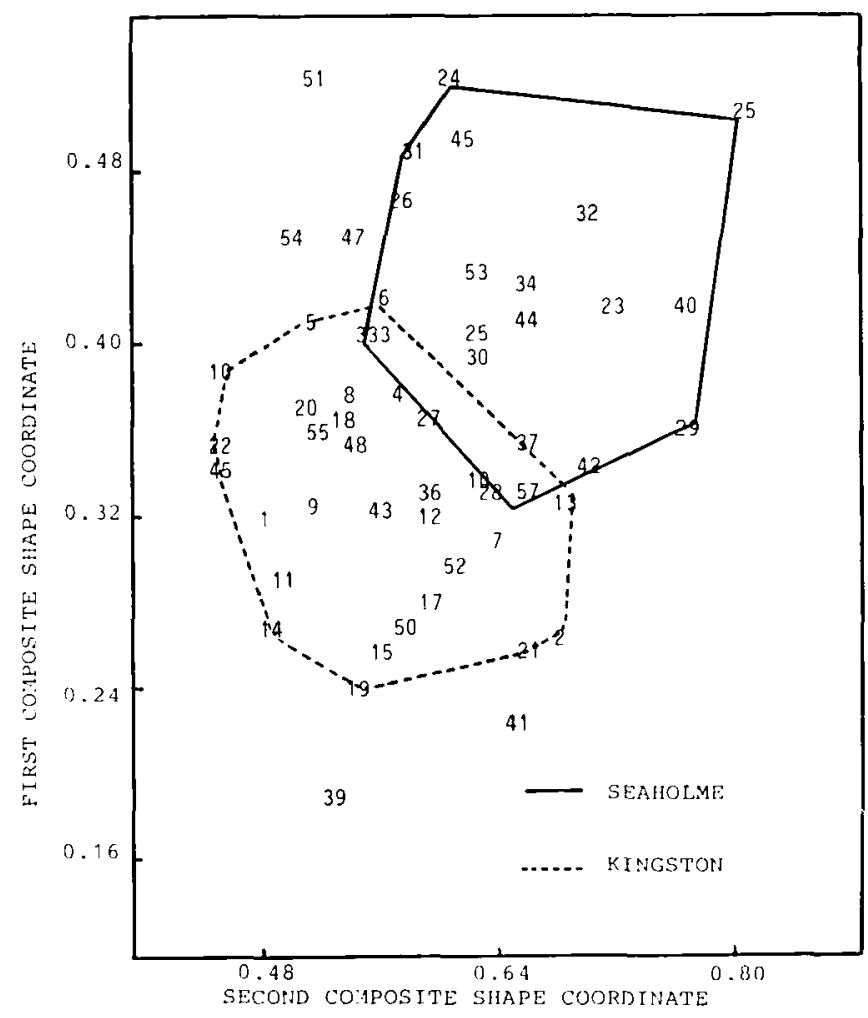

Fig. 5. Separation of the samples from Seaholme and Kingston, based on the first set of landmarks (Fig. 2B) and using shape-coordinates. 


\section{(c) Eigenshape analysis}

Our third analysis studied the figures of $M$. pumilus published by Hartmann (1982) by the method of eigenshape analysis of Lohmann (1983). This method locates analogues of principal components for the variation of curving outlines represented without regard for landmark locations. The method taps the same source of information as the complex Fourier analysis of Ferson et al. (1985) but begins from a representation of the outline in terms of its curving rather than its location.

Inasmuch as Hartmann's specimens were collected from environments having an annual temperature range of about $10^{\circ} \mathrm{C}$, and through the four months in 1975 less than $3^{\circ} \mathrm{C}$, it might be expected that the eigenshape analysis would uncover any more strongly marked differences. It was found that there is no trend in the plot of the first eigenshape against the second eigenshape.

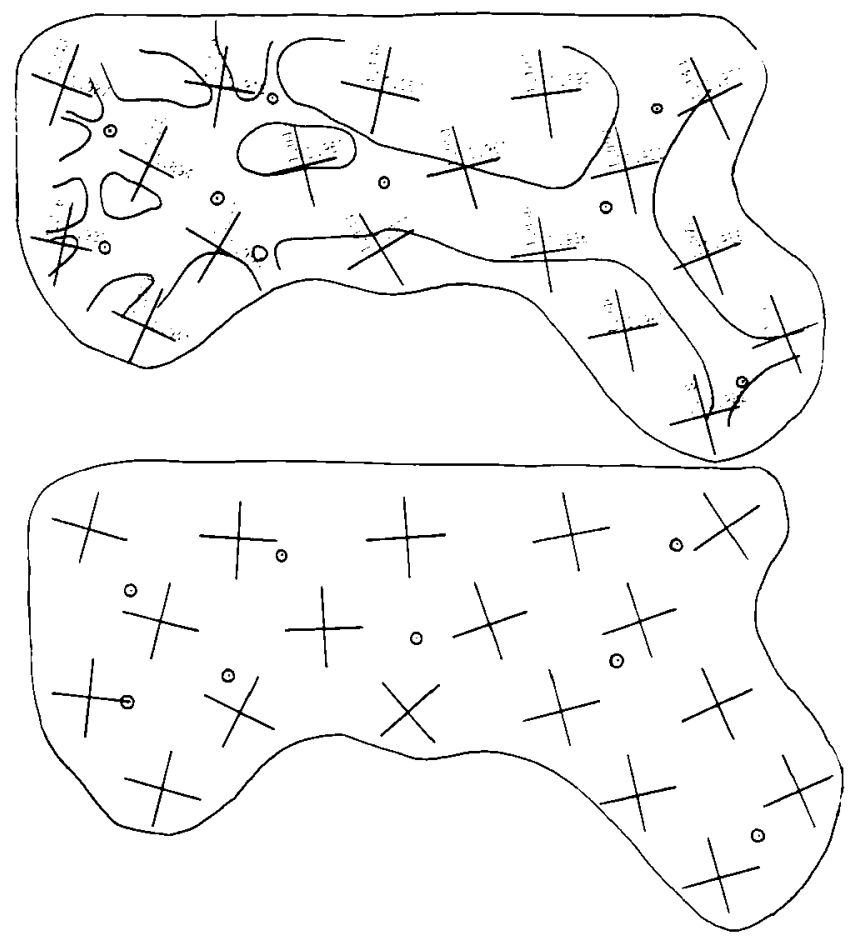

Fig. 6. Biorthogonal grids for the relationship between the ornamental patterns in the Kingston and Seaholme samples (Fig. 2B). The lower figure indicates the arbitrarily selected starting form with the "crosses" lying in a square mesh. The upper figure illustrates the deformed grid formed by shearing from the starting sample to the compared sample.

\section{ECOLOGICAL DISCUSSION}

Temperature changes are conceded generally to have a causative role re morphologic variations in taxa, even to inducing speciation when associated with oceanographic factors (Cronin, 1987). The known temperature range for living populations of $M$. pumilus is moderately large, Hartmann $(1979,1980,1981)$ recorded a range between $17.6-23.4^{\circ} \mathrm{C}$ for specimens collected by him during the austral summer of 1975 . His localities, from Eagle Bay, Cape Naturaliste, Western Australia to Bateman's Bay, New South Wales, have a wider geographic compass than those which provided our materials.

Annually, the variation in water temperature is known to be greater. At Oyster Harbour, southwestern Western Australia, McKenzie (1964) noted a range from $12.3^{\circ} \mathrm{C}$ in winter (June) to $25^{\circ} \mathrm{C}$ in summer (November-March) for the years 1961-1962. In Port Phillip Bay, Victoria, during 1950-1951 water temperature varied from below $10^{\circ} \mathrm{C}$ in July to nearly $22^{\circ} \mathrm{C}$ in January; and the vertical thermal stratification range was small, less than $3^{\circ} \mathrm{C}$ (Rochford, 1966).

Also germane is the temperature variation in geological time. McKenzie (1974, p. 159) noted that $M$. pumilus made its first appearance in southeastern Australia during the Neogene, thus it would have been present throughout those temperature variations which characterised glacio-eustatic sea level changes that influenced the coast of southern Australia during the Pleistocene. Over the past 700,000 years, according to evidence collated by Gill (1986), sea level was highest in southeastern Australia about 110,000-125,000 years ago - Stage 5e of Shackleton (1969). The same level was identified previously in northern Spencer Gulf, South Australia (Belperio et al., 1984). We can assume that water temperature during Stage 5e were somewhat higher than today as confirmed by the occurrence in contemporaneous marine deposits near Warrnambool, Victoria of the warm water index gastropod Ninella torquata. There was an earlier warm water phase about 400,000 years ago, also marked by the occurrence of Ninella (Gill, 1986).

Thus, although our method precluded comparative experimental study of temperature effects upon aquaria populations of $M$. pumilus, the available data provide support for an interpretation that water temperature differences at the times of moult into adulthood afford some possible explanation for the degree of ornamental variation in $M$. pumilus encountered by our statistical study. This interpretation rests upon the entire spectrum of spatio-temporal temperature variations to which now geographically widespread populations have been subjected during vicariant dispersal since initiation of $M$. pumilus in the Victorian Neogene.

Over the known geographic range of $M$. pumilus, data comparable to those provided for water tempera- 
tures are also available for ambient water chemistry. Hartmann $(1979,1980,1981)$ noted salinity values of $37-38.5 \%$, and a pH around 8. McKenzie (1964) recorded an annual salinity range from $9 \%$ during winter river discharge maxima to $36.7 \%$ during summer in Oyster Harbour. Rochford (1966) gave an annual salinity range of $27.1-36.1 \%$ in Port Phillip Bay. Generally, inshore waters of southern Australia are well oxygenated, ranging, for example, from $83 \%$ of saturation $(4.7 \mathrm{ml} / 1)$ to $105 \%(6.6 \mathrm{ml} / 1)$ in Port Phillip Bay (Rochford, 1966). Available nutrients are adequate (McKenzie 1964, figs. 15, 16), characterised by an enrichment in nitrate nitrogen during periods of winter dilution by river discharges and a correlated depletion in inorganic phosphates (Rochford, 1966).

The likely effects of ambient water chemistry upon ostracod shells are undoubtedly complex and, until recently, were not well understood. The ostracod shell is the permineralised part of its cuticle and most of the calcite for each new moult is obtained exogenously (Graf, 1978) with a minor component being recycled from the previous moult (Rosenfeld, 1982). The organic framework for each moult is preregistered genetically, but the permineralising calcite, since it is in the main derived exogenously, is affected critically by ambient water chemistry. When the environment is deficient in carbonate - correlated to oxygen deficiency - the organic framework of the new moult is not fully (genotypically) mineralised. On the other hand, when the environment is supersaturated with respect to carbonate (as occurs diurnally in the tropics) the excess shell calcite tends to obscure species-specific features of the genotypic ornament. These effects are termed rhopic factor effects (McKenzie \& Peypouquet, 1984). Along the southern Australian coastline, excess of ambient carbonate is unlikely to be common let alone diurnal. Deficiencies in carbonate saturation are also unlikely to occur frequently although when they do the ornamental variation can be dramatic as illustrated for M. pumilus by Hartmann (1982, compare figs. 5,8 and 11 with the other figures on his pl. 1). Our landmark measures which are tied to the genotypic organic framework are unlikely to vary so dramatically. On balance, it seems that the small but real variations in size and shape that we have elucidated owe more to geographic distance and water temperature than to ambient water chemistry.

\section{SUMMARY}

Mutilus pumilus is a species of ostracod known to display ornamental variation as well as variation in shape. We find these variations to be very likely ecophenotypic. Notwithstanding the fact that conventional multivariate analysis (canonical variates) identified the geographical structure in the data (localities in Western Australia, South Australia and Victoria), the

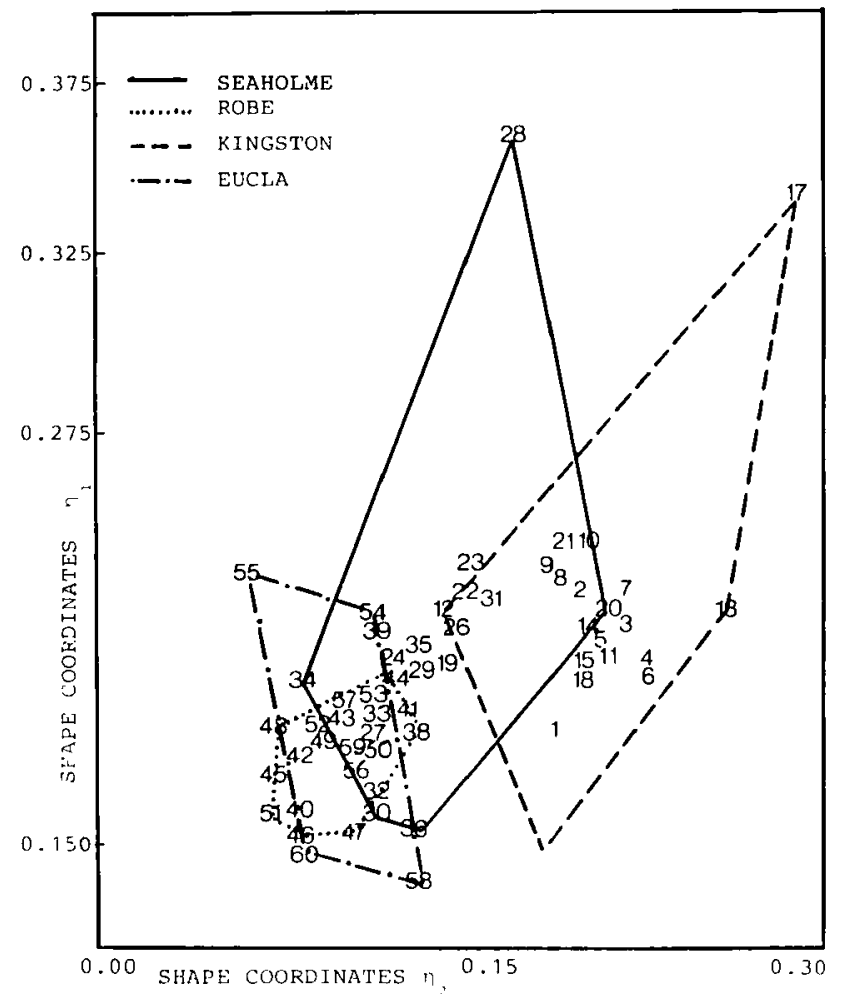

Fig. 7. Separation of samples by means of shapecoordinates computed for the landmarks located around the outline of the carapace (Fig. 2C).

techniques of geometric morphometrics were better able to interpret the variability of shape by locating the sector of the shell undergoing the more important shape changes and showing how these stresses might be distributed laterally over the ornament. An important finding of the study concerns the variability of the anteroventral zone of the carapace.

\section{ACKNOWLEDGEMENTS}

The main part of the preparation of this paper was carried out during Bookstein's stay in the Department of Historical Geology and Palaeontology, Uppsala, in April-May, 1986. The material was collected by McKenzie and his associates. Reyment was able to visit many of the localities in September, 1986, in McKenzie's company. Reyment and Bookstein wish to express their gratitude to the Swedish Natural Science Research Council for financing an important part of the work, including Bookstein's stay in Uppsala. The S.E.M. work was done by Mrs. Eva Reyment.

\section{Manuscript received December 1986 \\ Revised manuscript accepted September 1987}




\section{REFERENCES}

Abe, L. 1983. Population structure of Keijella bisanensis (Okubo) (Ostracoda, Crustacea). J. Fac. Sci. Univ. Tokyo, 20, 443-488.

Belperio, A. P., Smith, B. W., Plach, H. A., Nittrouer, C. A., DeMaster, D. J., Prescott, J. R., Hails, J. R. \& Gostin, V. A. 1984. Chronological studies of the Quaternary marine sediments of northern Spencer Gulf, South Australia. Mar. Geol., 61, 265-296.

Blackith, R. E. \& Reyment, R. A. 1971. Multivariate Morphometrics. Academic Press, London.

Bodergat, A. M. 1983. Les Ostracodes, témoins de leur environnement: approche chimique et écologique en milieu lagunaire et océanique. Docum. Lab. Géol. Lyon, 88, 1-246.

Bookstein, F. L. 1978 The Measurement of Biological Shape. Lecture Notes in Biomathematics, 24, Springer Verlag, New York.

Bookstein, F. L. 1986. Size and shape spaces for landmark data in two dimensions. Statistical Science, 1, 181-242.

Bookstein, F. L., Chernoff, B., Elder, B., Humphries, J., Smith, G. \& Strauss, R. 1985. Morphometrics in Evolutionary Biology. Academy of Natural Sciences, Philadelphia.

Cronin, T. M. 1987. Evolution, biogeography and Systematics of Puriana: evolution and speciation in Ostracoda III. J. Paleont., 61, Suppl. to No. 3, Paleontol. Soc. Mem. 21, $1-71$.

Ducasse, O. 1981. Etude populationniste du genre Cytherella (Ostracodes) dans les faciès bathyaux du Paléog̀ene. Intérêt dans la reconstitution des paléoenvironnements. Bull. Inst. Géol. Bassin Aquitaine, Bordeaux, 30, 161-186.

Ducasse, O. 1983. Etude des populations du genre Protoargilloecia (Ostracodes) dans les faciès bathyaux du Paléogène Aquitaine. Geobios, 16, 273-283.

Ducasse, O. \& Cirac, P. 1981. La faune de Mutilus (Ostracodes: Hemicytheridae) de la région de Zemmours (Maroc nord-occidental) à la fin de Miocène et au Pliocène. Géol. Médit., 8, 87-100.

Ducasse, O. \& Rousselle, L. 1979. Les Hammatocythere (Ostracodes) de l'Oligocène aquitain. Bull. Inst. Géol Bassin Aquitaine, Bordeaux, 25, 221-255.

Ferson, S., Rohlf, F. J. \& Koehn, R. 1985. Measuring shape variation of two-dimensional outlines. Systematic Zoology, 34, 59-68.

Gill, E. D. 1986. The Warrnambool District. In McKenzie, K. G. (Compiler), 'Shallow Tethys 2' Tertiary field excursion booklet, 11-13. RMIHE Printery, Wagga Wagga.

Graf, F. 1978. Les sources de calcium pour les Crustacés venant de muer. Arch. Zool expér. gén., 119, 143-161.

Hartmann, G. 1979. Teil 3. Die Ostracoden der Ordnung Podocopida Müller, G. W., 1894 der warm-temperierten (antiborealen) West- und Südwestküste Australiens (zwischen Perth im Norden und Eucla im Süden). Mitt. hamb. zool. Mus. Inst., 76, 219-301.

Hartmann, G. 1980. Teil 5. Die Ostracoden der Ordnung Podocopida Müller, G. W., 1894 der warmtemperierten und subtropisch-tropischen Küstenabschnitte der Süd- und Südwestküste Australiens (zwischen Ceduna im Westen und Lakes Entrance im Osten). Mitt. hamb. zool. Mus. Inst., 77, 111-204.

Hartmann, G. 1981. Teil 7. Die Ostracoden der Ordnung Podocopida Müller, G. W., 1894 der subtropisch-tropischen Ostküste Australiens (zwischen Eden im Süden und
Heron-Island im Norden). Mitt. hamb. zool. Mus. Inst., 78, 97-149.

Hartmann, G. 1982. Variation in surface ornament of the valves of three ostracod species from Australia. In Bate, $\mathbf{R}$. H., Robinson, E. \& Sheppard, L. M. (Eds.), Fossil and Recent Ostracods, 365-380. Ellis Horwood Ltd., Chichester for British Micropalaeontological Society.

Keen, M. 1982. Intraspecific variation in Tertiary ostracods. In Bate, R. H., Robinson, E. \& Sheppard L. M., (Eds.), Fossil and Recent Ostracods, 380-405. Ellis Horwood Ltd. Chichester for British Micropalaeontological Society.

Lohmann, G. P. 1983. Eigenshape analysis of microfossils. A general morphometric procedure for describing changes in shape. Math. Geol., 15, 659-672.

McKenzie, K. G. 1964. The ecologic associations of an ostracode fauna from Oyster Harbour, a marginal marine environment near Albany, Western Australia. Pubbl. staz. zool., Napoli, 33 (suppl.), 421-461.

McKenzie, K. G. 1974. Cenozoic Ostracoda of southeastern Australia with the description of Hanaiceratina new genus. Geoscience and Man, 6, 153-182.

McKenzie, K. G. \& Peypouquet, J. P. 1984. Oceanic palaeoenvironment of the Miocene Fyansford Formation from Fossil Beach, near Mornington, Victoria, interpreted on the basis of Ostracoda. Alcheringa, 8, 291-303.

Reif, W. -E. 1984. Artabgrenzung und das Konzept der evolutionären Art in der Paläontologie. Zeitschrift für Systematik und Evolutionsforschung, 22(4), 263-286.

Reyment, R. A. 1963 Studies on Nigerian Upper Cretaceous and Lower Tertiary Ostracoda; Part 2, Danian, Paleocene and Eocene Ostracoda. Stockh. Contr. Geol., 10, 1-286.

Reyment, R. A. 1983. Phenotypic evolution in microfossils Evolutionary Biology, 16, 209-254.

Reyment, R. A. (In press). Evolutionarily significant polymorphism in marine ostracods. Journ. Palaeont. Soc. Japan.

Rochford, D. J. 1966. Port Phillip Survey 1957-1963. Hydrology. Mem. natl. Mus. Vict., 27, 107-118.

Rosenfeld, A. 1982. The secretion process of the ostracod carapace. In Bate, R. H., Robinson, E. \& Sheppard, L. M. (Eds.), Fossil and Recent Ostracods, 12-14. Ellis Horwood, Chichester for British Micropalaeontological Society.

Shackleton, N. J. 1969. The last interglacial in the marine and terrestrial records. Proc. R. Soc. London, Ser. B, 174, $135-154$

Thompson, D'Arcy, W. 1942. On Growth and Form. University Press, Cambridge, 1116 pp. 2nd Edition.

Zahn, C. R. \& Roskies, R. Z. 1972. Fourier description for plane closed curves. IEEE Trans. on Computers, C-21(3), 269-281. 